\title{
Early experience with endoscopic foraminotomy in patients with moderate degenerative deformity
}

\author{
Karthik Madhavan, MD, ${ }^{2}$ Lee Onn Chieng, ${ }^{2}$ BS, Lynn McGrath, MD, ${ }^{1}$ \\ Christoph P. Hofstetter, MD, PhD, ${ }^{1}$ and Michael Y. Wang, MD² \\ 'Department of Neurological Surgery, University of Washington, Seattle, Washington; and 2Department of Neurological Surgery \\ and The Miami Project to Cure Paralysis, University of Miami Miller School of Medicine, Miami, Florida
}

\begin{abstract}
OBJECTIVE Asymmetrical degeneration of the disc is one of the most common causes of primary degenerative scoliosis in adults. Coronal deformity is usually less symptomatic than a sagittal deformity because there is less expenditure of energy and hence less effort to maintain upright posture. However, nerve root compression at the fractional curve or at the concave side of the main curve can give rise to debilitating radiculopathy.

METHODS This study was a retrospective analysis of 16 patients with coronal deformity of between $10^{\circ}$ and $20^{\circ}$. All patients underwent endoscopic foraminal decompression surgery. The pre- and postoperative Cobb angle, visual analog scale (VAS), 36-Item Short Form Health Survey (SF-36), and Oswestry Disability Index scores were measured.

RESULTS The average age of the patients was $70.0 \pm 15.5$ years (mean $\pm \mathrm{SD}$, range 61-86 years), with a mean followup of $7.5 \pm 5.3$ months (range $2-14$ months). The average coronal deformity was $16.8^{\circ} \pm 4.7^{\circ}\left(\right.$ range $\left.10^{\circ}-41^{\circ}\right)$. In 8 patients the symptomatic foraminal stenosis was at the level of the fractional curve, and in the remaining patients it was at the concave side of the main curve. One of the patients included in the current cohort had to undergo a repeat operation within 1 week for another disc herniation at the adjacent level. One patient had CSF leakage, which was repaired intraoperatively, and no further complications were noted. On average, preoperative VAS and SF-36 scores showed a tendency for improvement, whereas a dramatic reduction of VAS, by $65 \%(p=0.003)$, was observed in radicular leg pain.

CONCLUSIONS Patients with mild to moderate spinal deformity are often compensated and have tolerable levels of back pain. However, unilateral radicular pain resulting from foraminal stenosis can be debilitating. In select cases, an endoscopic discectomy or foraminotomy enables the surgeon to decompress the symptomatic foramen with preservation of essential biomechanical structures, delaying the need for a major deformity correction surgery.
\end{abstract}

http://thejns.org/doi/abs/10.3171/2015.11.FOCUS15511

KEY WORDS endoscopic spine surgery; coronal deformity; scoliosis

$\mathrm{G}$ IVEN the rapid aging of our population, degenerative scoliosis is a substantial burden for our society. ${ }^{23}$ Several factors lead to progression of adult deformity, including osteoporosis, asymmetrical degeneration of the disc, previous spine surgeries, and trauma. ${ }^{3}$

Coronal deformity is defined as greater than $10^{\circ}$ of curve seen in the lumbosacral and thoracolumbar spine. It is better tolerated than sagittal deformity by patients because it requires less expenditure of energy. ${ }^{3}$ On the other hand, coronal deformity is well known to cause significant foraminal stenosis at the fractional curve or at the concave side of the main curve, with resultant radicular pain. Frequently, patients with coronal deformity seek medical treatment for radicular pain rather than debilitating back pain. ${ }^{22}$ We present our early experience with outpatient endoscopic foraminotomies in patients with coronal deformity of more than $10^{\circ}$ with predominant unilateral radicular pain.

\section{Methods}

A prospective database of 80 patients who underwent endoscopy was screened for patients with coronal deformity of greater than $10^{\circ}$. The main complaint had to be radicular leg pain rather than back pain. These patients underwent awake endoscopic foraminal decompression on the side of concavity. Patient demographic data, operative details, clinical outcome, complications, and radiographic

ABBREVIATIONS LL = lumbar lordosis; MCS = mental component summary; ODI = Oswestry Disability Index; PCS = physical component summary; PI = pelvic incidence; PT = pelvic tilt; SF-36 = 36-Item Short Form Health Survey; SVA = sagittal vertical axis; VAS = visual analog scale.

SUBMITTED October 1, 2015. ACCEPTED November 10, 2015.

INCLUDE WHEN CITING DOI: 10.3171/2015.11.FOCUS15511. 
images were reviewed. We measured outcomes using preand postoperative Cobb angle, visual analog scale (VAS), 36-Item Short Form Health Survey (SF-36), and Oswestry Disability Index (ODI) scores. Approval for this study was obtained from the institutional review boards of the University of Miami Miller School of Medicine and the University of Washington School of Medicine. In Tables $1-3$, means are presented as the mean $\pm \mathrm{SD}$.

\section{Results}

\section{Patient Characteristics}

A total of 20 endoscopic foraminotomies were performed in a cohort of 16 patients consisting of 7 men and 9 women (Tables 1-3). The average age in our cohort was $70.0 \pm 15.5$ years (mean $\pm \mathrm{SD}$, range $61-86$ years) and the mean follow-up period was $7.5 \pm 5.3$ months (range 2-14 months). The majority of patients (75\%) had a single-level foraminotomy, whereas the rest $(25 \%)$ received 2 -level foraminotomies. Procedures were most commonly performed at the L4-5 level (55\%), followed by the L5-S1 (20\%), L3-4 (10\%), L2-3 (10\%), and L1-2 (5\%) levels (Figs. 1-3).

\section{Radiological Outcome}

Preoperatively, baseline radiographic parameters such as coronal Cobb angle, lumbar lordosis (LL), pelvic incidence (PI), pelvic tilt (PT), and sagittal balance were measured in all patients. The mean coronal angle of the main curve was $16.8^{\circ} \pm 4.7^{\circ}$ (range $\left.10^{\circ}-41^{\circ}\right)$, whereas the mean coronal segmental angle was $7.7^{\circ} \pm 4.8^{\circ}$ (range $1^{\circ}-14^{\circ}$ ). Meanwhile the mean LL angle was $36.5^{\circ} \pm 13.7^{\circ}$ $\left(\right.$ range $20^{\circ}-57^{\circ}$ ). The PI was $48.7^{\circ} \pm 12.9^{\circ}$, and the PT was $23.0^{\circ} \pm 7.6^{\circ}$. Last, the sacral slope was $32.5^{\circ} \pm 15.6^{\circ}$. The sagittal balance was on average $51.4^{\circ}$ and less than $5 \mathrm{~cm}$ in all patients included in the current cohort. There were no significant changes observed in terms of postoperative sagittal and coronal alignment parameters. The Scoliosis Research Society-Schwab adult deformity classification ${ }^{18}$ showed no major coronal deformity, except 1 lumbar curve of more than $30^{\circ}$. The other results were as follows: PI - LL findings of $0\left(<10^{\circ}, \mathrm{n}=9\right),+\left(10^{\circ}-20^{\circ}, \mathrm{n}=7\right)$,

TABLE 1. Demographic characteristics of 16 patients with coronal deformity receiving endoscopic discectomy

\begin{tabular}{cc}
\hline \multicolumn{1}{c}{ Variable } & Value $(\%)$ \\
\hline Mean age in yrs, \pm SD & $70.0 \pm 15.5$ \\
\hline Sex (\% male) & $7(44.8)$ \\
\hline Total no. of discectomies* & 20 \\
\hline 1-level & $12(75)$ \\
\hline 2-level & $4(25)$ \\
\hline Level of discectomy & $1(5)$ \\
\hline L1-2 & $2(10)$ \\
\hline L2-3 & $2(10)$ \\
\hline L3-4 & $11(55)$ \\
\hline L4-5 & $4(20)$ \\
\hline L5-S1 & $7.5 \pm 5.3$ \\
\hline Mean follow-up period in mos, \pm SD
\end{tabular}

* There were 20 discectomies in 16 patients.
TABLE 2. Baseline radiographic features of included patients

\begin{tabular}{lc}
\hline \multicolumn{1}{c}{ Feature } & Value $\left(^{\circ}\right) \pm \mathrm{SD}$ \\
\hline Mean regional lumbar coronal angle & $16.8 \pm 4.7$ \\
\hline Mean coronal segmental angle & $7.7 \pm 4.8$ \\
\hline Mean regional LL angle & $36.5 \pm 13.7$ \\
\hline PI & $48.7 \pm 12.9$ \\
\hline PT & $23.0 \pm 7.6$ \\
\hline Sacral slope & $32.5 \pm 15.6$ \\
\hline
\end{tabular}

and $++\left(>20^{\circ}, \mathrm{n}=4\right)$; PT findings of $0\left(<20^{\circ}, \mathrm{n}=13\right),+$ $\left(20^{\circ}-30^{\circ}, \mathrm{n}=5\right)$, and $++\left(>30^{\circ}, \mathrm{n}=2\right)$; and sagittal vertical axis (SVA) findings of $0(<4 \mathrm{~cm}, \mathrm{n}=6)$ and $+(4 \mathrm{~cm}-9.5$ $\mathrm{cm}, \mathrm{n}=14)$.

\section{Functional Outcome}

All our patients were discharged home on the day of surgery, and no intraoperative, perioperative, or immediate postoperative complications were encountered. There were no readmissions in the first 90-day period, except for 1 patient who had disc herniation adjacent to the index level. Several outcome measures were used to assess improvement in symptoms and quality of life. Significant pain improvement for both low-back and leg pain was observed. There was significant reduction of VAS by $50 \%$ $(\mathrm{p}=0.026)$ for the low-back pain symptom. Whereas, dramatic reduction of VAS by $65 \%(\mathrm{p}=0.003)$ was observed in radicular leg pain. Meanwhile, as for quality of life measures, ODI seem to be reduced by $32 \%$ after surgery, whereas the SF-36 mental component summary (MCS) was increased by 3\% ( $=0.669)$, although neither parameter reached statistical significance. However, interestingly, the SF-36 physical component summary (PCS) was decreased by $10 \%(\mathrm{p}=0.209)$.

\section{Complications or Adverse Outcome}

All patients were neurologically stable after the endoscopic procedure. Most patients had transient numbness or weakness that resolved within 12 weeks following the procedure. This is probably due to the proximity of the procedure to a dorsal root ganglion. Motor weakness was noted in 1 patient, which could have been from the disc being very proximal to the nerve root. One patient had CSF leakage at the axilla of the nerve root. He had undergone a previous microdiscectomy in another hospital and the symptoms had resolved. He suffered a car accident and recurrence of disc herniation 1 week later. $\mathrm{He}$

TABLE 3. Analysis of clinical outcome using the Student paired 2-tailed t-test

\begin{tabular}{lcccc}
\hline Clinical Outcome & Preop & $\begin{array}{c}\text { Postop at Latest } \\
\text { Follow-Up }\end{array}$ & \% Change & $\begin{array}{c}p \\
\text { Value }\end{array}$ \\
\hline VAS-back* & $7.0 \pm 4.4$ & $3.5 \pm 3.2$ & -50 & 0.026 \\
\hline VAS-leg* & $6.4 \pm 3.7$ & $1.9 \pm 3.5$ & -65 & 0.003 \\
\hline ODI & $32.5 \pm 13.8$ & $22.2 \pm 9.9$ & -32 & 0.094 \\
\hline SF-36 (PCS) & $47.7 \pm 4.4$ & $42.8 \pm 4.5$ & -10 & 0.209 \\
\hline SF-36 (MCS) & $48.0 \pm 3.8$ & $49.6 \pm 11.8$ & +3 & 0.669 \\
\hline${ }^{*} p<0.05$. & & & &
\end{tabular}




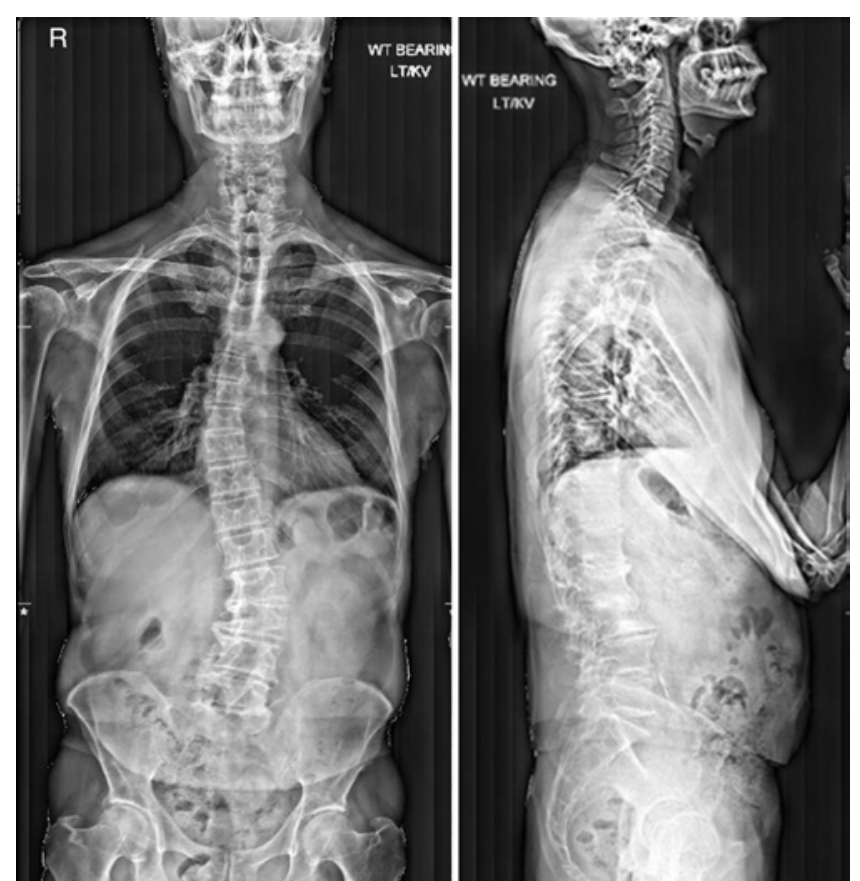

FIG. 1. Patient is a 73-year-old man who presented with predominant radicular left lower-extremity pain down to the dorsal aspect of his foot. He did have chronic back pain, but it was quite tolerable. Left: Preoperative anteroposterior radiograph obtained to assess scoliosis shows coronal deformity of $20^{\circ}$. Right: Preoperative lateral radiograph shows that the patient is quite well balanced sagittally.

underwent endoscopic discectomy but presented to the emergency room 2 weeks later with positional headaches and fluid collection at the site of surgery. On exploration of the original microdiscectomy incision, he was noted to have a CSF leak at the axilla of the nerve root, which was primarily repaired. It is unclear if the incidental durotomy happened at the time of the first microdiscectomy or during the endoscopic procedure. Another patient was an amputee below the knee, and due to the severity of the disc herniation he underwent right-sided L3-4 discectomy due to his approximate distribution of pain. The plan was to reschedule him 1 week later if the symptoms did not resolve because he also had a smaller disc on the right L4-5 level.

\section{Discussion}

Life expectancy in the US, as noted by the Centers for Disease Control in 2012, is almost 79 years, and has been increasing (https://www.census.gov/prod/2010pubs/ p25-1138.pdf). It is estimated that by the year 2050, there will be 88 million people older than 65 years in the US (https://www.census.gov/population/projections/files/ analytical-document09.pdf). Given that the incidence of spine surgery is higher in patients older than 65 years compared with younger individuals, ${ }^{23}$ it is not surprising that the number of patients undergoing spine surgeries has been increasing. ${ }^{16}$ Longer life expectancy correlates with increased incidence of additional spine surgery due to adjacent-level breakdown, iatrogenic instability, infection, and other postoperative complications. ${ }^{6}$ Every "redo" spine surgery in itself is quite complicated, and more so when it
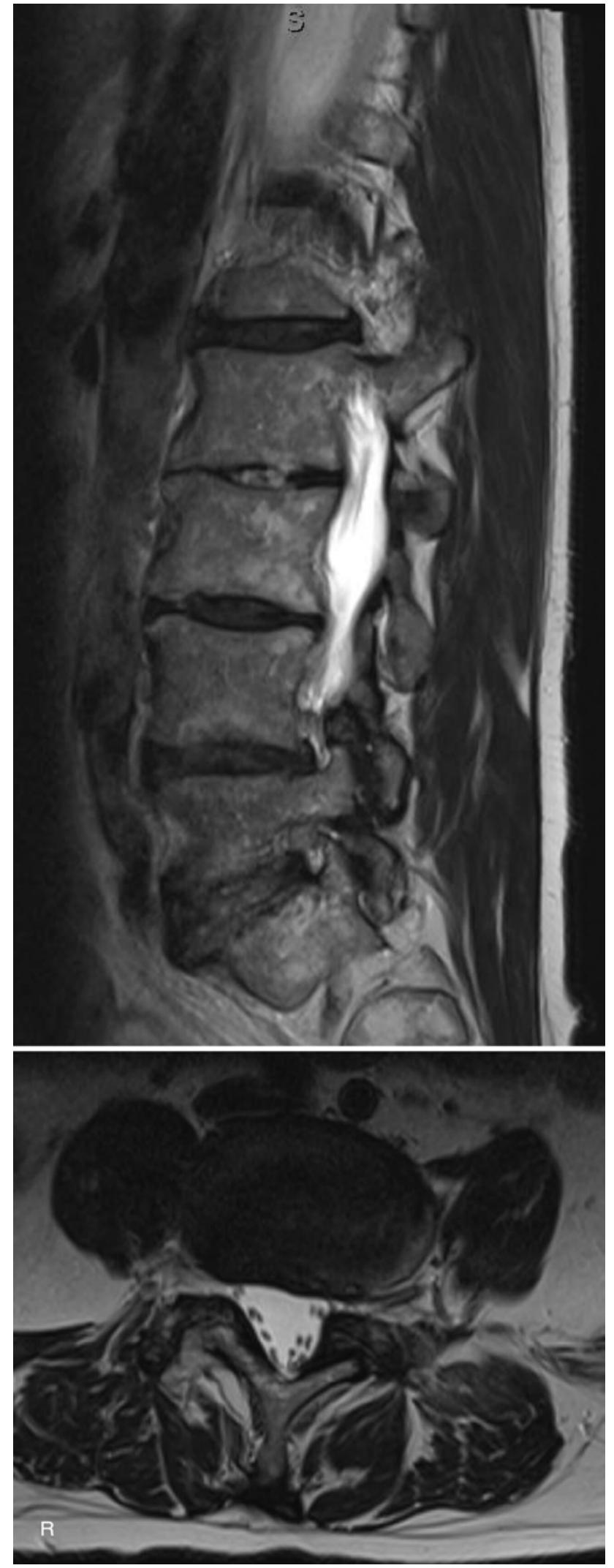

FIG. 2. Preoperative T2-weighted MR images. Upper: Sagittal view shows severe compression of the $L 4-5$ nerve root on the left side. Lower: Axial view shows compression on the left $L 4-5$ foramen, with nerve root compression. 

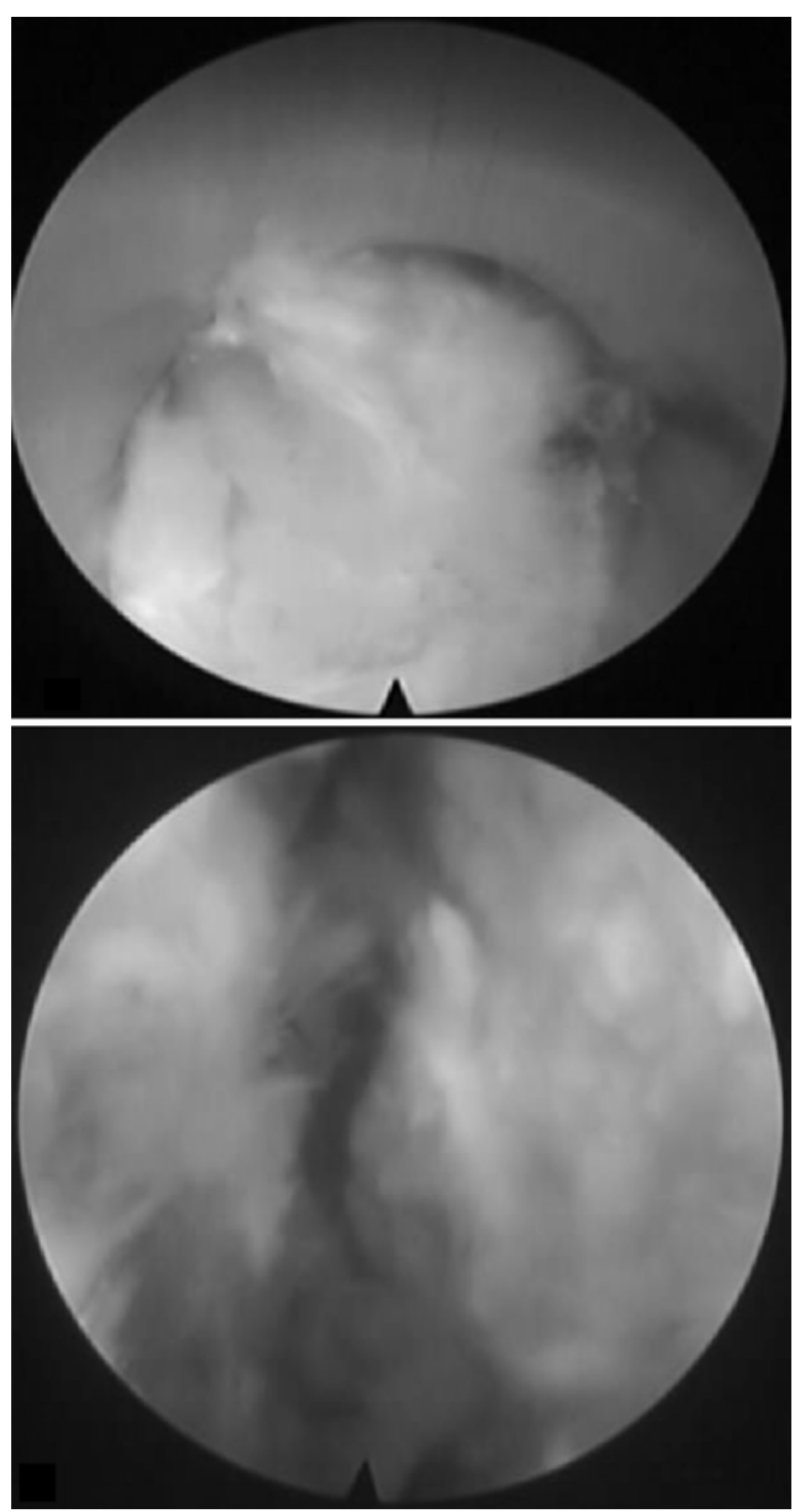

FIG. 3. Upper: Preoperative image of disc herniation visible through the endoscope after opening through the anulus with a reamer. Lower: Postoperative image shows optimal resection of the disc herniation.

is performed in the elderly population. ${ }^{20}$ Addressing the entire spine as a single unit enables the surgeon to plan the possible future procedures with minimal complications..$^{13,25}$ Endoscopic discectomy enables the preservation of all the essential structures with minimal complications, although there is a steep learning curve for beginners. ${ }^{10,11}$ Several papers show that the results are comparable to open or tube microdiscectomy, ${ }^{2,8}$ including in the elderly population. ${ }^{11}$ The approach itself does not interfere with the traditional deformity exposure and minimizes dural scar and complications related to revision surgeries. In addition, the transforaminal approach avoids scar tissue caused by previous traditional discectomies performed via an interlaminar corridor. ${ }^{21}$ We perform these endoscopic discectomies in awake patients, which reduces the perioperative morbidity of intubation as well as anesthesia complications. ${ }^{1,2}$

It is not uncommon to see patients with deformity who present in clinic for radicular pain due to foraminal stenosis that is caused by compression of the nerve root on the concave side of the curve as a result of disc herniation, ligament hypertrophy, and facet hypertrophy. These same patients have tolerable levels of back pain from deformity. The management of focal radicular pain in deformity is a matter of debate. ${ }^{4}$ Several studies have proposed microdiscectomy, ${ }^{26}$ minimally invasive shaving system, ${ }^{7}$ lateral lumbar interbody fusion, ${ }^{4}$ and full deformity surgery. If 1-level fusion is proposed, the surgeon has to make sure that this level is not fused in an abnormal position, interfering so as to worsen the curve or make future deformity management harder. The cohort included in the current study includes patients who underwent endoscopic surgery for foraminal stenosis with concomitant presence of coronal deformity of $10^{\circ}$ or more. The goal of our surgery was to alleviate the radicular leg pain, which improved by $65 \%$ on the ODI. Our SF-36 scores were quite high in the beginning, which may be the reason for minimal improvement. These measures of quality of life did not reach statistical significance due to the small number of patients included and the short follow-up period. During the follow-up (8-13 months), $87.5 \%$ of the patients had complete resolution of radicular leg pain, and the majority continued to do better, with tolerable levels of back pain from their deformity. Given the short follow-up in this early report, the durability of these preliminary results will require further investigation with longer follow-up and large series of patients.

Surgical indications in patients with adult deformity is mainly to alleviate the pain, halt the curve progression, and improve neurological deficit. ${ }^{12}$ The goal of the surgery is to restore balance and improve lifestyle. ${ }^{14,17,24}$ Adult deformity surgery in itself is quite a morbidity-producing surgery. ${ }^{9}$ In a recent publication O'Neill et al. revealed that among 120 patients who underwent deformity surgery, there were major surgical complications in $27 \%$ of them and 25\% had reoperations. Most of the patients had undergone previous spine surgeries, and not only were the complications high in these patients but also patient satisfaction was low, as noted in the ODI and SF-36 scores. ${ }^{15}$ Another study, by Ayhan et al., also revealed that in 121 patients who underwent adult deformity correction, a total of 114 complications (59 major, 55 minor) and 1 death were noted. ${ }^{5}$ At Level II evidence there is significant quality of life improvement, ${ }^{20}$ and with complications, the final outcome of radiological correction did not change. ${ }^{19}$ So unless there are strong indications to undertake deformity correction surgery, smaller procedures aiming to provide symptomatic relief from radicular pain may be worth considering.

\section{Conclusions}

Endoscopic foraminotomy may be a feasible treatment option for select patients with a moderate coronal deformity who have isolated unilateral radicular pain. The highly targeted nature of endoscopic foraminotomies may partially avoid exacerbation of a deformity from iatrogenic 
destabilization, which can be a sequela of traditional open laminectomy or discectomy surgeries. Endoscopic procedures may be performed as awake surgeries, with minimal disruption of the critical biomechanical structures in the lumbar spine. Further studies to better define ideal surgical candidates as well as to investigate the durability of symptomatic relief are needed. Meanwhile we will continue to follow up these patients over several more months and intend to publish longer outcomes in 2 years.

\section{References}

1. Ahn Y, Lee SH, Park WM, Lee HY: Posterolateral percutaneous endoscopic lumbar foraminotomy for L5-S1 foraminal or lateral exit zone stenosis. Technical note. J Neurosurg 99 (3 Suppl):320-323, 2003

2. Ahn Y, Oh HK, Kim H, Lee SH, Lee HN: Percutaneous endoscopic lumbar foraminotomy: an advanced surgical technique and clinical outcomes. Neurosurgery 75:124-133, 2014

3. Ailon T, Smith JS, Shaffrey CI, Lenke LG, Brodke D, Harrop JS, et al: Degenerative spinal deformity. Neurosurgery 77 (Suppl 4):S75-S91, 2015

4. Alimi M, Hofstetter CP, Tsiouris AJ, Elowitz E, Härtl R: Extreme lateral interbody fusion for unilateral symptomatic vertical foraminal stenosis. Eur Spine J 24 (Suppl 3):346352, 2015

5. Ayhan S, Aykac B, Yuksel S, Guler UO, Pellise F, Alanay A, et al: Safety and efficacy of osteotomies in adult spinal deformity: what happens in the first year? Eur Spine J [epub ahead of print], 2015

6. Deyo RA, Mirza SK, Martin BI, Kreuter W, Goodman DC, Jarvik JG: Trends, major medical complications, and charges associated with surgery for lumbar spinal stenosis in older adults. JAMA 303:1259-1265, 2010

7. Dickinson LD, Phelps J, Summa CD, Vanichkachorn JS, Jeshuran WR, Randall JB, et al: Facet-sparing decompression with a minimally invasive flexible microblade shaver: a prospective operative analysis. J Spinal Disord Tech 26:427-436, 2013

8. Evins AI, Banu MA, Njoku I Jr, Elowitz EH, Härtl R, Bernado A, et al: Endoscopic lumbar foraminotomy. J Clin Neurosci 22:730-734, 2015

9. Fu KM, Bess S, Shaffrey CI, Smith JS, Lafage V, Schwab F, et al: Patients with adult spinal deformity treated operatively report greater baseline pain and disability than patients treated nonoperatively; however, deformities differ between age groups. Spine (Phila Pa 1976) 39:1401-1407, 2014

10. Jasper GP, Francisco GM, Telfeian AE: Clinical success of transforaminal endoscopic discectomy with foraminotomy: a retrospective evaluation. Clin Neurol Neurosurg 115:19611965, 2013

11. Jasper GP, Francisco GM, Telfeian AE: A retrospective evaluation of the clinical success of transforaminal endoscopic discectomy with foraminotomy in geriatric patients. Pain Physician 16:225-229, 2013

12. Kanter AS, Shaffrey CI, Mummaneni P, Wang MY, Uribe JS: Introduction: Adult spinal deformity: pathophysiology and corrective measures. Neurosurg Focus 36(5):Introduction, 2014

13. Maggio D, Ailon TT, Smith JS, Shaffrey CI, Lafage V, Schwab F, et al: Assessment of impact of standing longcassette radiographs on surgical planning for lumbar pathology: an international survey of spine surgeons. J Neurosurg Spine 23:581-588, 2015

14. Mummaneni PV, Shaffrey CI, Lenke LG, Park P, Wang MY, La Marca F, et al: The minimally invasive spinal deformity surgery algorithm: a reproducible rational framework for decision making in minimally invasive spinal deformity surgery. Neurosurg Focus 36(5):E6, 2014

15. O'Neill KR, Lenke LG, Bridwell KH, Neuman BJ, Kim HJ, Archer KR: Factors associated with long-term patientreported outcomes after three-column osteotomies. Spine J 15:2312-2318, 2015

16. Rajaee SS, Bae HW, Kanim LE, Delamarter RB: Spinal fusion in the United States: analysis of trends from 1998 to 2008. Spine (Phila Pa 1976) 37:67-76, 2012

17. Scheer JK, Mundis GM, Klineberg E, Hart RA, Deviren $\mathrm{V}$, Nguyen S, et al: Post-operative recovery following adult spinal deformity surgery: comparative analysis of age in 149 patients during 2 year follow up. Spine (Phila Pa 1976) 40:1505-1515, 2015

18. Schwab F, Ungar B, Blondel B, Buchowski J, Coe J, Deinlein D, et al: Scoliosis Research Society-Schwab adult spinal deformity classification: a validation study. Spine (Phila Pa 1976) 37:1077-1082, 2012

19. Smith JS, Shaffrey CI, Lafage V, Schwab F, Scheer JK, Protopsaltis T, et al: Comparison of best versus worst clinical outcomes for adult spinal deformity surgery: a retrospective review of a prospectively collected, multicenter database with 2-year follow-up. J Neurosurg Spine 23:349-359, 2015

20. Soroceanu A, Burton DC, Diebo BG, Smith JS, Hostin R, Shaffrey CI, et al: Impact of obesity on complications, infection, and patient-reported outcomes in adult spinal deformity surgery. J Neurosurg Spine 23:656-664, 2015

21. Telfeian AE: Endoscopic foraminotomy for recurrent lumbar radiculopathy after TLIF: technical report. Surg Neurol Int 6:62, 2015

22. Toyone T, Tanaka T, Kato D, Kaneyama R, Otsuka M: Anatomic changes in lateral spondylolisthesis associated with adult lumbar scoliosis. Spine (Phila Pa 1976) 30:E671E675, 2005

23. Waldrop R, Cheng J, Devin C, McGirt M, Fehlings M, Berven $\mathrm{S}$ : The burden of spinal disorders in the elderly. Neurosurgery 77 (Suppl 4):S46-S50, 2015

24. Wang MY: Less invasive mini-open adult spinal deformity surgery. Neurosurg Focus 35 (2 Suppl):Video 1, 2013

25. Wang MY, Madhavan K: Mini-open pedicle subtraction osteotomy: surgical technique. World Neurosurg 81:843. e11-843.e14, 2014

26. Yeom JS, Kim KH, Hong SW, Park KW, Chang BS, Lee $\mathrm{CK}$, et al: A minimally invasive technique for L5-S1 intraforaminal disc herniations: microdiscectomy with a tubular retractor via a contralateral approach. J Neurosurg Spine 8:193-198, 2008

\section{Disclosures}

Dr. Wang is a consultant for DePuy Spine, Aesculap Spine, joimax, and K2M. He is a patent holder with DePuy Spine. Dr. Hofstetter is a consultant for Johnson \& Johnson and for InVivo Therapeutics.

\section{Author Contributions}

Conception and design: Madhavan, Hofstetter. Acquisition of data: Madhavan, Chieng, McGrath, Wang. Analysis and interpretation of data: all authors. Drafting the article: Madhavan. Critically revising the article: Madhavan. Administrative/techni$\mathrm{cal} /$ material support: Wang. Study supervision: Wang.

\section{Correspondence}

Karthik Madhavan, Lois Pope Life Center, 1095 N.W. 14th Terrace, Miami, FL 33126. email: drkarthik19@gmail.com. 